Review

\title{
Current Application and Technology of Functional Multineuron Calcium Imaging
}

\author{
Shigehiro NAMIKI ${ }^{a, b}$ and Yuji IKeGaYA ${ }^{*, a, c}$ \\ ${ }^{a}$ Laboratory of Chemical Pharmacology, Graduate School of Pharmaceutical Sciences, The University of Tokyo; \\ Tokyo 113-0033, Japan: ${ }^{b}$ Graduate School of Life and Environmental Sciences, University of Tsukuba; \\ Ibaraki 305-8572, Japan: and ${ }^{c}$ Precursory Research for Embryonic Science and Technology (PRESTO), \\ Japan Science and Technology Agency; 5 Sanbancho, Chiyoda-ku, Tokyo 102-00075, Japan.
}

Received September 4, 2008

\begin{abstract}
Here we describe recent applications and technical advancements of functional multineuron calcium imaging (fMCI), which monitors the firing activity of more than a thousand neurons through their somatic $\mathrm{Ca}^{2+}$ signals. fMCI is used for analysis of various neural circuits under normal and pathological conditions. In vitro fMCI is made more sophisticated by using multipoint illumination and scanning technology with spinning-disk and low-laser-intensity imaging, electron-multiplying charge-coupled device cameras, etc. In vivo fMCI is still developing. We review optical technologies for fast scanning imaging, deep tissue imaging, and recording from moving animals.
\end{abstract}

Key words calcium imaging; functional multineuron calcium imaging; large-scale recording; scanning; spinning disk

\section{INTRODUCTION}

Highly organized nervous systems provide animals with the ability to adapt to unpredictably changing external environments, but such ability has not yet been achieved by an artificial system. Researchers have investigated the brain by monitoring parameters such as morphological change, metabolic activity, and gene expression. The action potential emitted by a neuron is definitely one of the most important parameters because it has fast dynamics and allows specific communication with other cells. A considerable amount of knowledge about action potentials has been obtained by the intracellular recording method using sharp glass electrodes. ${ }^{1-4)}$ This electrophysiological technique, however, can monitor the activity of only a few cells. Because neuronal activity is spatially and temporally organized in a network, large-scale monitoring techniques are required for further understanding of the mechanisms underlying neural information processing.

Some neuroimaging techniques are designed to record optical signals derived from the electrical activity of cells and are often used with intracellular recording in a complementary style. For example, voltage-sensitive dyes are used to monitor firing and subthreshold activity across a neuronal population. ${ }^{5-7)}$ Imaging with single cell resolution, however, can be achieved in animals, such as mollusks, in which neuronal somata are large, ${ }^{8,9)}$ but it is rarely attained in mammals

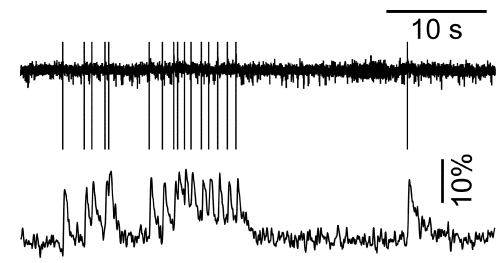

Fig. 1. Optical Monitoring of Action Potentials

Traces represent simultaneous cell attached recording (top) and $\mathrm{Ca}^{2+}$ imaging (bottom) from a cortical neuron. Note timgins of $\mathrm{Ca}^{2+}$ transients are correlated with those of action potentials. This allows us to reconstruct a series of action potentials from calcium traces alone. because of the low signal-to-noise ratio. ${ }^{10)}$ This problem will be overcome in future by development of high performance genetically encoded voltage sensors. ${ }^{11-14)}$

In this respect, at present $\mathrm{Ca}^{2+}$ imaging provides one of the most useful techniques to monitor neuronal activity with cellular resolution. In mammalian neurons, an action potential usually results in a transient increase in intracellular $\mathrm{Ca}^{2+}$ concentrations (Fig. 1). By taking advantage of this $\mathrm{Ca}^{2+}$ signal, one can detect the time when an action potential occurs in the neuron. ${ }^{15-18)}$ Indeed, some studies have used chemical $\mathrm{Ca}^{2+}$ indicators as a reporter of neuronal activity and reconstructed the spiking activity of more than a thousand neurons. ${ }^{19-21)}$ This method is called functional multineuron calcium imaging (fMCI). In past years, we have exploited this technique and analyzed neural circuit dynamics. ${ }^{20,22-30)}$ In this review, we focus on recent applications of fMCI and technical advancements in optics and engineering which are supporting further development of the fMCI.

\section{fMCI APPLICATION IN BRAIN SLICES}

To monitor neuronal circuits with cellular resolution, we need to optically section a sample tissue so as not to contaminate the images of neurons of interest with scattered light and out-of-focus images. For this purpose, confocal microscopy and two-photon excitation microscopy are widely used. Because experimental manipulations such as intracellular recordings and pharmacological experiments are relatively easy, in vitro slice preparations are useful to analyze the basic properties of neuronal circuits. In application of fMCI in brain slice preparations, confocal microscopy is often selected because of its usability and low cost.

Conventional Confocal Laser Scanning Microscopy: Single Pinhole In conventional confocal microscopy, excitation light is focused to a relatively small spot in which the power density is highest and hence energetically favorable to excite fluorescent dye. However, practically, dyes outside the focus are also excited, reducing the signal-to-noise ratio in the obtained image. In confocal microscopy, such extra-exci- 
tation is removed with a small aperture called a pinhole which functions as a spatial filter ${ }^{31)}$; that is, light emitted from the focal spot efficiently passes through the pinhole, while the vast majority of emission light arising from the outside area is physically blocked. To acquire a two-dimensional or three-dimensional image of a specimen, the focal spot is moved with servomotor-controlled mirrors called Galvano-mirrors, servomotor-controlled stages, etc. Scanned emission light is detected by a photomultiplier tube (PMT). PMT detects a photon via a photoelectric effect and amplifies the signal $10^{5}-10^{8}$ times through multiple charged cathodes, in which an incoming photoelectron produces secondary electrons. The amplified electrons are converted into electric currents by an anode.

Nipkow Spinning Disk Confocal Microscopy: Spinning Disk with Multi-Pinholes The second implementation is the use of multi-point illumination with many pinholes on a spinning plate termed a Nipkow disk. A rotating spinning disk has multiple pinholes through which laser lines embody multisite focal illumination and detection. The commercially available apparatus, Yokogawa's spinning disk, is further sophisticated. The system uses an additional spinning disk that contains a $c a .20000$ microlens array for light convergence on the corresponding pinholes on a Nipkow disk. ${ }^{32)}$ The light focusing also helps reduce scattering light, improving the signal-to-noise ratio. In addition, pinholes are strategically aligned in space to achieve uniform illumination over the field of view. ${ }^{33,34)}$ The latest version of Yokogawa's spinning disk, CSU-X1, is more improved in terms of the light use efficiency, about two-fold higher than the previous version, CSU-10. In CSU-X1, reduction of mechanical noise from its disk-driving part allows realization of 10000 revolutions per minute. Because the helical pinhole distribution covers the whole field of view every $30^{\circ}$ of disk rotation, CSU-X1 enables the maximum sampling rate of $2000 \mathrm{~Hz}$.

Charge-Coupled Device Technology Spinning disk confocal microscopy simultaneously illuminates multiple sites, meaning that PMT is not a suitable photodetector due to the difficulty of the integration process. Although recently maximum $8 \times 8$ arrayed PMTs, H7546B (Hamamatsu, Shizuoka, Japan), have recently been developed, ${ }^{35)}$ the spatial resolution is not sufficient for fMCI. For spinning disk confocal studies, a charge-coupled device (CCD), which transfers electric charges using a potential well, is widely used. The CCD image sensor works with multiple steps as follows: i) transduction of photon into electric charges through the photoelectric effect, ii) accumulation and transfer of electric charges (at the CCD part), and iii) read-out of electric charge to electrical current by an on-chip floating diffusion amplifier.

Since development of the $\mathrm{CCD},{ }^{36)}$ several important innovations have occurred. First, in frame transfer CCD, the storage area is covered with an opaque metal film for charge transfer. A detected photon rapidly moves to this storage part, and its charge is transferred to a read-out resistor without a mechanical shutter. Importantly, the image area acquires a new signal during the period that the storage area transfers the previous signal to a shift register. This architecture enables fast acquisition rates. Moreover, the transfer CCD does not contain a transfer line in its CCD array, and thus the aperture ratio is almost $100 \%$. Second, in back-illu- minated or back-thinned CCD, the quantum efficiency is significantly improved. In a normal device, a gate oxide film, polysilicon electrodes, and a coating film are placed on the front surface of the CCD, and thus incoming light is partially absorbed or reflected. This structure reduces the maximum quantum efficiency to less than $40 \%$. Thinning of back-side substrate of the CCD to $20 \mu \mathrm{m}$ and back-side illumination improve the quantum efficiency up to $c a$. $90 \%$. Third, the most important innovation for measuring a weak optical signal is electron-multiplying CCD (EM-CCD) technology. ${ }^{37,38)}$ The biggest factor for the signal-to-noise ratio of a sufficiently cooled CCD is read-out noise generated at a floating diffusion amplifier, which converts electric charges to voltage. EM-CCD employs on-chip multiplication of electric charges before read-out by this amplifier. A charge multiplier is located between a serial register and the floating diffusion amplifier and multiplies passing electric charges via the impact ionization effect. A high electrical field applied at the multiplying gate in a charge multiplier provides high kinetic energy to electrical charges. This causes impact with other materials in a semiconductor, and a single electron produces a pair of a hole and an electron, resulting in multiplication of the electrical charges. Because multiplication of these charges occurs before read-out by the floating diffusion amplifier, the read-out noise becomes negligible so that a single photon is detectable.

We use back-illuminated EM-CCD cameras (DV-860, DV865, and DV-887; Andor Technology, Belfast, U.K.), which use all the technologies mentioned above. Although a drawback of CCD may be its lower signal-to-noise ratio as compared to PMT, CCD can take images much faster and thus is suitable for fMCI with high temporal resolution (Fig. 2). When images are scanned at high frame rates, the rotation speed of the spinning disk of CSU-X1 and the refresh rate of CCD should be synchronized to avoid band noise. ${ }^{39)}$ In frame-transfer mode, we can monitor an image area at $2000 \mathrm{~Hz}$. To our knowledge, this is the fastest confocal full scanning achieved to date in the world.

Dye Loading and Staining Problem $\mathrm{Ca}^{2+}$ indicators are classified into two groups: synthetic compounds and genetically encoded proteins. In fMCI, synthetic acetoxymethyl (AM)-ester probes are usually used. AM ester is a remnant to enhance the biological membrane permeability of the $\mathrm{Ca}^{2+}$ indicator. ${ }^{40)}$ Since the first application of AM-ester probes, fMCI in slice preparation is primarly carried out in the cortex, hippocampus, and cerebellum. ${ }^{15,41-43)}$ Recently, fMCI has been applied to other brain regions, including the olfactory bulb, ${ }^{44)}$ striatum, ${ }^{45,46)}$ and spinal cord. ${ }^{47)}$

We systematically examined the loading of Oregon Green 488 BAPTA-1AM, one of the most widely used $\mathrm{Ca}^{2+}$ indicator in $\mathrm{fMCI}$, in acute mouse brain slices and identified the difference in staining efficiency among brain regions. ${ }^{30)}$ From our data on acute brain slices, fMCI is further applicable to thalamus, pons, brainstem, and amygdala, which regions have been inaccessible in in vivo brains so far. A critical disadvantage of acute brain slices is the difficulty of dye loading in slices prepared from adult animals; in general, it is very difficult to stain acute brain slices from rodents at $20 \mathrm{~d}$ of postnatal age, while pressure injection of the $\mathrm{Ca}^{2+}$ indicator in vivo produces good loading in adult animals. ${ }^{48)}$ A second group of $\mathrm{Ca}^{2+}$ indicators, i.e., genetically encoded $\mathrm{Ca}^{2+}$ indi- 


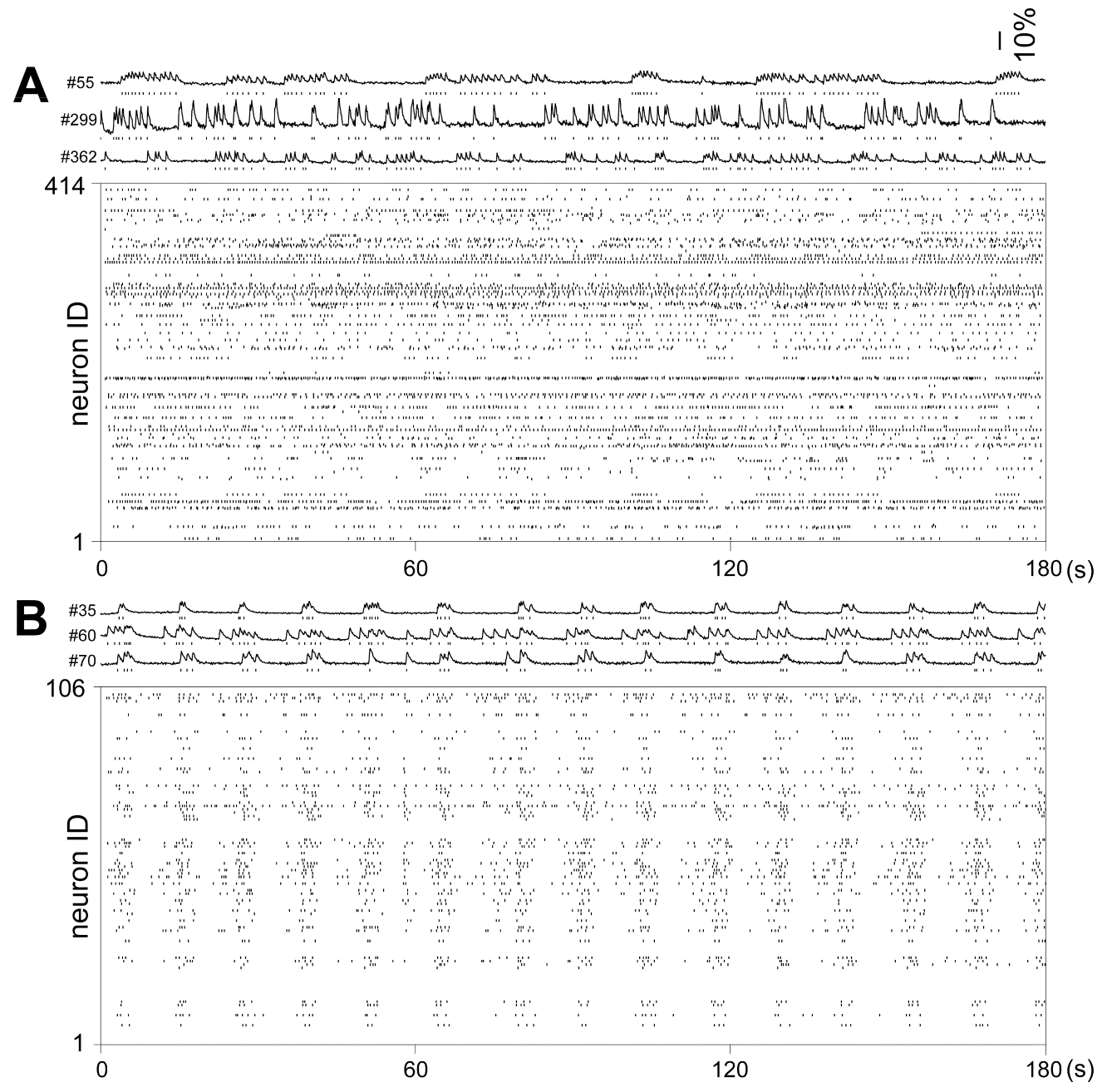

Fig. 2. Representative Data of Time-Lapse Imaging of Cortical Network Activity

Different pattens of spontaneous activity are shown, i.e., non-periodic activity (A) and periodic slow oscillations (B). Representative somatic $\mathrm{Ca}^{2+}$ signals (top) and raster plots of $\mathrm{Ca}^{2+}$ transient onsets (bottom) in mouse lateral entorhinal cortical slices. Each row in the raster plot represents a single neuron, and each mark indicates the onset of a single $\mathrm{Ca}^{2+}$ transient.

cators, are being developed. ${ }^{49-59)}$ Although several genetically encoded $\mathrm{Ca}^{2+}$ sensors have been shown to detect the firing activity of a single neuron, it is still difficult to achieve single-spike resolution, probably due to their large molecular size and slow dynamics. ${ }^{56,60,61)}$

Probing Neurons and Network Architecture with fMCI fMCI is used to record spatiotemporal activity patterns of neural circuits with single-cell resolution. Monitoring the multineuronal activity with $\mathrm{fMCI}$ has revealed that the cortical microcircuits generate non-random, rather precise spatiotemporal patterns during spontaneous activity ${ }^{19,20,62)}$ and that patterns of externally evoked activity are strikingly similar to those of spontaneous activity. ${ }^{63)}$ Although other techniques, such as extracellular multiunit recording, are also able to monitor multineuronal activity, ${ }^{64)}$ a benefit of fMCI is that the multineuronal activity data contains geometrical information, that is, fMCI provides a location map as well as activity patterns of hundreds of neurons. Taking advantage of this asset, fMCI is being used as a probing tool for neurons of interest. ${ }^{65-71)}$ For example, single-cell activation with fMCI makes it possible to identify postsynaptic target cells, and conversely, simultaneous recording of synaptic input and fMCI enables the identification of presynaptic source cells. ${ }^{65,67)}$

Nikolenko et al. (2007) introduced a systematic probing strategy of functional synapses. ${ }^{71)}$ They combined fMCI with a high spatial resolution stimulation method using two photon-activated caged glutamate. ${ }^{72,73)}$ They use multiplexed laser beams through diffractive optical elements to multiply the focal spots of two-photon excitation and reliably excited neurons of interest. Serial activation of individual neurons provides a comprehensive input map, i.e., synaptic strength from all location-identified neurons in the field of view. In addition, the systematic activation of a small group of neurons reveals that brain slices show large-scale synchronized activity when a specific combination of neurons is simultaneously activated. ${ }^{71)}$ In this study, however, the timings of stimulation of different neurons are not strictly simultaneous, having time lags on the order of microseconds. One method to solve the stimulation delay is patterned optical stimulation. ${ }^{7,75)}$ This technique allows simultaneous stimulation of different locations in any desired spatial pattern that is created with a digital micromirror device or spatial light modulator. Recently developed optogenetic techniques, which manipulate ion channel gating directly by light, are another promising tool with higher temporal resolution, although 
they do not have single cell resolution to date, nor do they undergo two-photon excitation. ${ }^{76-80)}$ Further improvement of spatial resolution of optogenetic tools and their stimulation hold promise of more effective optical probing techniques. ${ }^{81)}$

Online signal processing is also important in fMCI studies. Several studies proposed automatic signal processing algorithms to select the regions of interest $\mathrm{t}^{19,82,83)}$ and to detect spike events from time series of a calcium trace. ${ }^{18,25,84)}$ Realtime closed-loop systems ${ }^{85)}$ are useful for further development of online analyses, such as experiments with eventdriven stimulation.

\section{fMCI APPLICATION IN VIVO}

Two-Photon Excitation Microscopy Living tissue is turbid, and both excitation and emission light are scattered. Deep brain tissues in vivo are accessible with two-photon microscopy, which utilizes simultaneous two-photon absorption to an electron higher energy orbit. Two-photon absorption is a non-linear optical phenomenon that requires high energy density. ${ }^{86,87)}$ To obtain such high density, a laser is pulsed through a mode-lock oscillator that generates femtosecond or picosecond pulses by using a beat from fixed-phase coherence across different resonance frequencies. ${ }^{88-93)}$ Due to the nonlinearity, two-photon absorption takes place only within a very small focal spot so that two-photon microscopy does not require a pinhole. Because light to excite widely used fluorescence probes is near-infrared, two-photon excitation reaches deeper areas than one-photon excitation.

Application in in Vivo Neuronal Circuits In the past years, fMCI has been utilized in in vivo experiments with mammalian species. ${ }^{17,21,94-101)}$ An excellent application of in vivo fMCI was done in cat primary visual cortex. Cerebral cortical areas are functionally organized; adjacent cortical neurons have similar response profiles, forming a cortical column. For example, haptic information of the body is mapped onto the somatosensory cortex. In visual areas, orientation and direction information is mapped onto the primary visual cortex. ${ }^{102)}$ Previous studies have suggested that cortical columns are segregated by functional borders. ${ }^{103,104)}$ However, the response property (gradual or sharp) of neurons near the border between cortical columns was unknown because spatial resolution was insufficient in multi-unit recording $(c a .65 \mu \mathrm{m})$ or other imaging techniques $(c a .100 \mu \mathrm{m})$. Ohki et al. (2005) recorded the $\mathrm{Ca}^{2+}$ signal from the primary visual cortex of anaesthetized cats with a high spatial resolution of about $1 \mu \mathrm{m} .{ }^{95)}$ Across the functional border, the orientation/direction selectivity changes suddenly at the single cell level, and this discontinuity is maintained in different depths of the cortex. Hence, the functional border is sharp and precise. The same authors also applied fMCI to the pinwheel, another type of functional border. ${ }^{21)}$ In this way, fMCI successfully resolves many long-standing problems about neocortical organization.

In vivo fMCI has begun to be applied to analyze neuronal disease. ${ }^{105)}$ Winship and Murphy (2008) monitored the recovery process of somatosensory cortex layer $2 / 3$ neurons after stroke. ${ }^{101)}$ In normal animals, somatosensory cortical subregions that respond to forelimb and hindlimb stimulation are separated by sharp functional borders without region overlapping. Four weeks after stroke, the subregion that responds to forelimb stimulation enlarges and overlaps with the neighboring subregion of hindlimb stimulation. Response selectivity increases in almost all neurons at this stage. By 8 weeks after stroke, response selectivity again becomes sharp, and a new response map is created. This is the first evidence showing the process of circuit rewiring with single-cell resolution. Further, combination of fMCI and manipulative techniques, such as single-cell aberration and gene expression, will be a novel methodology with which to treat neurological disorders. ${ }^{106,107)}$

In vivo fMCI is also applied in non-mammalian organisms. Because of their small body size, various forms of application are possible under in vivo conditions. $\mathrm{fMCI}$ is often used in the zebrafish brain. ${ }^{84,108-116)}$ This is powerful because the body is transparent and also because monitoring and even manipulation of behavior is relatively easy. For example, Orger et al. (2008) identified a neuronal population that commands swimming behavior. ${ }^{114)}$ In awake conditions, the fish reliably shows a turning or forward swimming behavior in response to drifting grating stimuli. They monitored the activity of spinal projection neurons, which are retrogradely labeled with dextran-conjugated dye, in response to the same stimuli and found that stimuli that drive distinct behaviors activate distinct subsets of neurons. In insects, the signal-tonoise ratio is not enough to detect single action potentials, but the fluctuations of $\mathrm{Ca}^{2+}$ signal correlate with changes in the firing rate of the neuron. ${ }^{60,117-119)}$ In these experiments, however, the relationship between somatic $\mathrm{Ca}^{2+}$ signal and action potential generation should be examined before imaging, because recent studies with non-mammalian species demonstrated that somatic $\mathrm{Ca}^{2+}$ does not always reflect the spiking activity; For example, action potentials do not cause somatic $\mathrm{Ca}^{2+}$ transients in some types of olfactory bulb interneurons in tadpoles. ${ }^{120)}$ Moreover, subthreshold membrane potential fluctuations affect somatic $\mathrm{Ca}^{2+}$ signals in projection neurons in the locust antennal lobe. ${ }^{119)}$

Technical Advance for Fast Recording: Scanning Technology Commercially available two-photon microscopy usually uses single-point illumination and thus requires sequential scanning point-by-point in a field, whereas spinningdisk confocal microscopy employs multi-point illumination and thus acquires an entire field at the same time. In in vivo fMCI, in particular, the sampling rate is substantially low, because two-photon microscopy is usually used. There are three solutions to improve temporal resolution (Fig. 3).

The first solution is to optimize the laser trajectory to scan neurons of interest with the minimal path length. Conventional confocal and two-photon microscopy uses two Galvanometer-controlled mirrors to scan a two-dimensional (2D) plane. By controlling an objective lens with a piezoelectric device, Göbel et al. achieved three-dimensional tra-

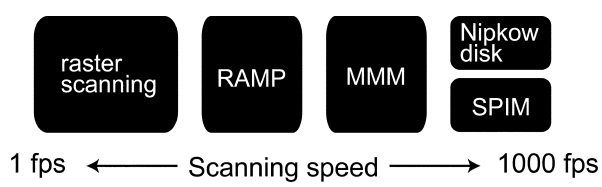

Fig. 3. Comparison of Scanning Speed

Microscopic techniques described in this review are compared, including laser scanning microscopy (LSM) with raster scanning, random-access multiphoton (RAMP), microscopy, multifocal multiphoton microscopy (MMM), single-plane illumination microscopy (SPIM), and Nipkow spinning disk confocal microscopy. 
jectory scanning in the neocortex in vivo. ${ }^{121,122)}$ In contrast to the conventional two-photon scanning method, which requires repeated raster scanning at different depths to obtain a three-dimensional image, ${ }^{21,84,95,113)}$ their system scans any given points with any desired trajectory and thus effectively traces neurons of interest with a short path length, enabling fast recording. Göbel et al. (2007) used inertia-limited continuous scanning patterns, such as spiral and Lissajous trajectories, because they used Galvanometer-controlled mirrors for point scanning. ${ }^{121)}$ Thus, inertia-free scanning methods are more appropriate for faster scanning.

Random-access multiphoton microscopy offers a solution to resolve this issue. ${ }^{123)}$ In an acoustic medium such as tellurium dioxide, lead molybdate, or fused silica, sound waves cause diffraction of light. ${ }^{124-126)}$ In random-access multiphoton microscopy with acousto-optic deflectors, the frequency of sound waves adjusts the pitch of a diffraction grating, controlling the direction of a light beam. This technique was first applied to scanning microscopy ${ }^{127)}$ and has been extended to deal with 2D sampling. ${ }^{128-132)}$ This scanning unit contains no physically movable object, and thus is inertia-free and qualitatively different from the Galvanometer-based unit. More recently, acousto-optic deflector-based three-dimensional scanning has been implemented with a combination of four acousto-optic deflectors. ${ }^{133-135)}$ To date, the application of random-access multiphoton microscopy has been limited to physiological recording from the dendritic $\mathrm{Ca}^{2+}$ signal of a small neuronal population, ${ }^{130,135,136)}$ but it is undoubtedly applicable to large-scale fMCI. In addition to acousto-optic deflector technology, micromirror array scanning also realizes nearly inertia-free, multi-point illumination ${ }^{137)}$; as the mirror movement is minimized, it is nearly random-access scanning. ${ }^{138,139)}$

The second solution is multifocal multiphoton microscopy; this microscopy employs multi-point two-photon excitation. Multi-beams are generated by a rotating disk ${ }^{140}$ ) or beam splitter, ${ }^{141)}$ and the light receiving element is a CCD array. The acquisition rate is proportional to the number of excitation foci. Niesner et al. (2007) systematically evaluated multi-point excitation with 64 beams. ${ }^{142)}$ Although the lightpenetration depth is slightly shallower than conventional twophoton microscopy which uses a single beam and PMT, the signal-to-noise ratio is almost the same within $200 \mu \mathrm{m}$ beneath the sample surface; the acquisition speed is approximately 60 times faster. A current drawback of multifocal multiphoton microscopy is lower signal-to-noise ratios at deeper regions. Kim et al. (2007) examined the penetration depth by multifocal multiphoton microscopy with multichannel PMTs and succeeded in improving the signal-to-noise ratio, although the spatial resolution of multichannel PMTs is insufficient for fMCI $(8 \times 8, \mathrm{H} 7546 \mathrm{~B}$, Hamamatsu Photonics, Hamamatsu, Japan). ${ }^{143)} \mathrm{Ji}$ et al. (2008) report that the splitting-laser-pulse method improves the signal-to-noise ratio and reduces photodamage and photobleaching. ${ }^{144)}$ Although multifocal multiphoton microscopy has not been applied to in vivo vertebrate species, it has been shown to work in in vivo insect brains ${ }^{145)}$ and acute mouse brain slices. ${ }^{68)}$

The third solution is single (or selective) plane illumination microscopy. This microscopy uses planar illumination with a light sheet generated by a cylinder lens, allowing illumination of a broad area at the same time. ${ }^{146-149)}$ An objec- tive lens and a CCD array are positioned perpendicularly to a laser beam to cover a large area at the same depth. Like twophoton microscopy, it does not require a pinhole for optical sectioning, because regions at depths outside the focus plane are not excited. The low cost is one merit of this method. Holekamp et al. (2008) used this optical system to perform fMCI in mice and revealed the spatiotemporal pattern of pheromone-evoked activation of vomeronasal receptor neurons and second-order olfactory neurons in the accessory olfactory bulb. ${ }^{150)}$

Recording from Deep Area That Is Inaccessible with Normal Light Microscopy To date, fMCI application in vivo has been limited to easily accessible nervous systems. The penetration depth of two-photon microscopy is limited to less than $1 \mathrm{~mm}$ in living neuronal tissue. ${ }^{151-153)}$ Thus, in vivo fMCI is currently performed only in the near-surface brain regions such as neocortex and cerebellum; deeper brain areas such as thalamus, hippocampus, and brainstem cannot be reached from the brain surface. A simple solution for recording from such deep tissues is to use fiberoptics technology, which is widely used in telecommunications. ${ }^{154)}$ This has indeed been carried out with one-photon microscopy ${ }^{155,156)}$ and two-photon microscopy. ${ }^{157)}$ Optical fiber is composed of a core with high refractive index and an external clad with low refractive index, and light is transmitted by total internal reflection within the core. The initial applications of optical fiber for functional recording did not attain good spatial resolution.

Microendoscopy is another option for imaging from deep subcortical areas. In this system, a small lens is directly inserted into neuronal tissue, and collected light is sent to the scanning system. The diameters of commercially available objective lenses usually range from 10 to $30 \mathrm{~mm}$ and are too large to insert living tissue without damage, but stick-type objectives with tip diameters of $300-1000 \mu \mathrm{m}$ have recently been developed by the Olympus Coporation. ${ }^{158)}$ The gradient-index (or graded-index) (GRIN) rod lens has also attracted much attention. In this lens, the refraction index is graded along its longitudinal axis ${ }^{159)}$; and thus the lens has the ability to focus light. Due to its flat surface, the working distance is long, and the numerical aperture is relatively large. Diameter of the gradient-index rod lens can be reduced to $300 \mu \mathrm{m}$. Microendoscopy with epifluorescence or confocal units is utilized for functional imaging in deep brain areas. ${ }^{158,160-162)}$ In addition, optical fiber is used for transmitting light to the scanning system, ${ }^{163,164)}$ and this gives mechanical flexibility to the microendoscopy. One problem in using optical fiber in two-photon excitation had been selfphase modulation, resulting in broadening and lowering spatial resolution. This was resolved by the recent implementation of photonic crystal fiber. ${ }^{165,166)}$

fMCI in Behaving Animals In vivo fMCI has to date mainly been performed in animals under anesthesia. The operations of neuronal circuits, however, differ between the awake and anesthetized brain. ${ }^{18,167-171)}$ Ideally, data should be obtained from freely-moving animals, but conventional microscopic setups are too large for moving animals to carry on their heads. Two solutions are posited to address this issue.

The first solution is to miniaturize optical systems for head mounting. Helmchen et al. (2001) made a compact micro- 
scope (as small as $25 \mathrm{~g}$ and $7.5 \mathrm{~cm}$ ) that was consisted of a small gradient-index rod lens, small PMTs, and a small scanner, and mounted it to the head of an adult rat. ${ }^{172)}$ Although recording from mobile animals was not achieved, they showed dendritic $\mathrm{Ca}^{2+}$ signal in anaesthetized animals. With a further improved version using a gradient-index rod lens, photonic crystal fiber, and fiber cantilever scanner $(0.6 \mathrm{~g}$ and $1 \mathrm{~mm}$ ), Engelbrecht et al. (2008) recorded the multineuronal $\mathrm{Ca}^{2+}$ signal of cerebellar Purkinje cells from anaesthetized animals. ${ }^{173)}$ This system utilized a vibrating cantilever for scanning, in which a piezo-electronic device actuates optical fiber to change illumination points, realizing two-dimensional scanning under minimal inertia conditions. This scanning method is also utilized by other groups. ${ }^{174,175)}$ There are various combinations to miniaturize microscope. For example, Vučinić and Sejnowski (2007) miniaturized microscope with an acousto-optic deflector-based scanning and realized a ca. $1000 \mathrm{~Hz}$ sampling rate. ${ }^{134)} \mathrm{A}$ fiber bundle combined with a gradient-index rod lens is also promising. ${ }^{176-179)}$ In this system, individual optical fiber works like a pinhole, yielding confocality of the scanned image. The scanning system can be positioned apart from the objective lens. A single microelectro-mechanical system mirror with piezo-electric or electromagnetic mechanics can scan a two-dimensional plane. ${ }^{180,181)}$ Kim et al. $(2004,2005)$ implemented a headmounted miniaturized two-photon microendoscope with multi-point illumination and multisite detection with a CCD camera. ${ }^{182,183)}$ Head-mounted miniaturized microscopy has not succeeded in functional recording from mobile animals; movement compensation is a key factor in realizing such functional recording.

Second, a technically easier solution is to use normal twophoton microscopy for a head-restrained animal on the treadmill system. The system has been developed for neuroethology using insects ${ }^{184-186)}$ and has been used for physiological recording during awake conditions. ${ }^{187)}$ Dombeck et al. (2007) applied this system to $\mathrm{FMCI}$ and reported simultaneous monitoring data of neurons and glial cells during behavior. ${ }^{188)}$ They performed two-photon imaging from mobile mice on a Styrofoam ball. The air is pressured under the ball so that the ball rotates smoothly. Running or walking behavior is monitored as a movement with infrared sensors. It is possible to simultaneously measure neuronal activity and quantify motor parameters such as velocity and acceleration. The authors found neuronal activity that correlated with mouse motion or running speed. Advantages of this approach with miniaturized microscopy are accessibility and better cost performance, whereas a disadvantage is that animals are restricted so that they may lose natural feedback signals. To solve this issue, a sensory-feedback system will be required for future experiments. Closed-loop systems have been developed to analyze tethered insects ${ }^{189-193)}$ and are now applied to rodents. ${ }^{194)}$ To simulate more real environments, virtual reality techniques will be a powerful tool for neuroethology. ${ }^{195,196)}$

\section{CONCLUDING REMARKS}

The current experimental system of fMCI for two-dimensional neuronal circuits is highly sophisticated, and further improvement of the performance depends on improvement in the loading efficiency of $\mathrm{Ca}^{2+}$ indicators and the combination with single-cell manipulating techniques. On the other hand, in vivo $\mathrm{fMCI}$ is still rudimentary, requiring the development of new technology. Notably, the emerging technologies mentioned above are versatile in many fields of biology and medicine, including cancer biology, immunology and drug discovery. ${ }^{197-199)}$ In this sense, multidisciplinary research and collaboration among neuroscience, pharmacology, medicine, and engineering are important. On the other hand, fMCI still has several methodological limitations to the monitoring of action potentials. For example, an onset of a $\mathrm{Ca}^{2+}$ transient delays a few milliseconds after action-potential generation. Moreover, the slow $\mathrm{Ca}^{2+}$ decay disturbs precise decoding of individual action potentials at high firing rates. We are seeking the possibility of monitoring action potentials by other optical signals or directly by voltage-sensitive dyes with single-cell resolution. Such techniques may replace fMCI in future.

Acknowledgements We are grateful to Rie Kimura, Takuya Sasaki, Naoya Takahashi, Ayako Hasegawa, Atsushi Usami, and Nahoko Kuga for daily insightful discussions. This work was supported in part by a Grant-in-Aid for Science Research on Priority Areas (Elucidation of neural network function in the brain: KAKENHI \#20019014), a Grantin-Aid for Science Research (KAKENHI \#19659013), and by The Asahi Glass Foundation.

\section{REFERENCES}

1) Hodgkin A. L., Huxley A. F., Nature (London), 144, 710-711 (1939).

2) Hodgkin A. L., Huxley A. F., J. Physiol., 117, 500-544 (1952).

3) Cole K. S., Curtis H. J., J. Gen. Physiol., 22, 649-670 (1939).

4) Naundorf B., Wolf F., Volgushev M., Nature (London), 440, 1060 1063 (2006)

5) Cohen L. B., Keynes R. D., Hille B., Nature (London), 218, 438441 (1968).

6) Cohen L. B., Salzberg B. M., Grinvald A., Annu. Rev. Neurosci., 1, $171-182$ (1978).

7) Tasaki I., Watanabe A., Sandlin R., Proc. Natl. Acad. Sci. U.S.A., 61, 833-888 (1968).

8) Wu J. Y., Tsau Y., Hopp H. P., Cohen L. B., Tang A. C., Falk C. X., J. Neurosci., 14, 1366-1384 (1994).

9) Briggman K. L., Abarbanel H. D., Kristan W. B. Jr., Science, 307, 896-901 (2005).

10) Yuste R., Tank D. W., Kleinfeld D., Cereb. Cortex, 7, 546-558 (1997).

11) Dimitrov D., He Y., Mutoh H., Baker B. J., Cohen L., Akemann W., Knöpfel T., PLOS ONE, 2, e440 (2007).

12) Sjulson L., Miesenböck G., J. Neurosci., 28, 5582-5593 (2008).

13) Lundby A., Mutoh H., Dimitrov D., Akemann W., Knöpfel T., PLoS ONE, 3, e2514 (2008).

14) Tsutsui H., Karasawa S., Okamura Y., Miyawaki A., Nat. Methods, 5, 683-685 (2008).

15) Yuste R., Katz L. C., Neuron, 6, 333-344 (1991).

16) Smetters D., Majewska A., Yuste R., Methods, 18, 215-221 (1999).

17) Kerr J. N. D., de Kock C. P. J., Greenberg D. S., Bruno R. M., Sakmann B., Helmchen F., J. Neurosci., 27, 13316-13328 (2007).

18) Greenberg D. S., Houweling A. R., Kerr J. N. D., Nat. Neurosci., 11, $749-751$ (2008).

19) Cossart R., Aronov D., Yuste R., Nature (London), 423, 283-288 (2003).

20) Ikegaya Y., Aaron G., Cossart R., Aronov D., Lampl I., Ferster D., Yuste R., Science, 304, 559-564 (2004).

21) Ohki K., Chung S., Kara P., Hübener M., Bonhoeffer T., Reid R. C., Nature (London), 442, 925-928 (2006).

22) Ikegaya Y., Le Bon-Jego M., Yuste R., Neurosci. Res., 52, 132-138 
(2005).

23) Sasaki T., Kimura R., Tsukamoto M., Matsuki N, Ikegaya Y., J. Physiol., 574, 195-208 (2006).

24) Sasaki T., Matsuki N., Ikegaya Y., J. Neurosci., 27, 517—528 (2007).

25) Sasaki T., Takahashi N., Matsuki N., Ikegaya Y., J. Neurophysiol., in press.

26) Takahashi N., Sasaki T., Usami A., Matsuki N., Ikegaya Y., Neurosci. Res., 58, 219-225 (2007).

27) Tsukamoto-Yasui M., Sasaki T., Matsumoto W., Hasegawa A., Toyoda T., Usami A., Kubota Y., Ochiai T., Hori T., Matsuki N., Ikegaya Y., PLoS ONE, 2, e1250 (2007).

28) Usami A., Matsuki N., Ikegaya Y., Neural Plast., 2008, 108969 (2008).

29) Usami A., Sasaki T., Satoh N., Akiba T., Yokoshima S., Fukuyama T., Yamatsugu K., Kanai M., Shibasaki M., Matsuki N., Ikegaya Y., J. Pharmacol. Sci., 106, 659-662 (2008).

30) Namiki S., Sasaki T., Matsuki N., Ikegaya Y., Int. J. Neurosci., in press.

31) Minsky M., US Patent No. 3013467 (1957)

32) Inoue S., Inoue T., Methods Cell Biol., 70, 87-127 (2002).

33) Tanaami T., Otsuki S., Tomosada N., Kosugi Y., Shimizu M., Ishida H., Appl. Opt., 41, 4704- 4708 (2002).

34) Wang E., Babbey C. M., Dunn K. W., J. Microsc., 218, 148-159 (2005).

35) Tagg N., De Santo A., Weber A., Cabrera A., Miyagawa P. S., Barker M. A., Lang K., Michael D., Saakyan R., Thomas J., Nucl. Instrum. Meth. A, 539, 668-678 (2005).

36) Boyle W. S., Smith G. E., Bell Syst. Tech. J., Apr., 587-593 (1970).

37) Madan S. K., Bhaumik B., Vasi J. M., IEEE Trans. Electron. Devices, 30, 694-699 (1983).

38) Jerram P., Pool P., Bell R., Burt D., Bowring S., Spencer S., Hazelwood M., Moody I., Catlett N., Heyes P., Proc. SPIE, 4306, 178 $186(2001)$.

39) Chong F. K., Coates C. G., Denvir D. J., McHale N., Thornbury K., Hollywood M., Proc. SPIE, 5324, 65 (2004).

40) Tsien R. Y., Nature (London), 290, 527-528 (1981).

41) Kettunen P., Demas J., Lohmann C., Kasthuri N., Gong Y., Wong R. O., Gan W. B., J. Neurosci. Methods, 119, 37-43 (2002).

42) Ghozland S., Aguado F., Espinosa-Parrilla J. F., Soriano E., Maldonado R., Eur. J. Neurosci., 16, 641-651. (2002).

43) Sullivan M. R., Nimmerjahn A., Sarkisov D. V., Helmchen F., Wang S. S., J. Neurophysiol., 94, 1636-1644 (2005).

44) Kapoor V., Urban N. N., J. Neurosci., 26, 11709-11719 (2006).

45) Osanai M., Yamada N., Yagi T., Neurosci. Lett., 402, 81-85 (2006).

46) Carrillo-Reid L., Tecuapetla F., Tapia D., Hernández-Cruz A., Galarraga E., Drucker-Colin R., Bargas J., J. Neurophysiol., 99, 14351450 (2008)

47) Wilson J. M., Dombeck D. A., Diaz-Rios M., Harris-Warrick R. M., Brownstone R. M., J. Neurophysiol., 97, 3118-3125 (2007).

48) Garaschuk O., Milos R. I., Konnerth A., Nat. Protoc., 1, 380-386 (2006)

49) Nakai J., Ohkura M., Imoto K., Nat. Biotechnol., 19, 137-141 (2001).

50) Hasan M. T., Friedrich R. W., Euler T., Larkum M. E., Giese G., Both M., Duebel J., Waters J., Bujard H., Griesbeck O., Tsien R. Y., Nagai T., Miyawaki A., Denk W., PLoS Biol., 2, e163 (2004).

51) Bozza T., McGann J. P., Mombaerts P., Wachowiak M., Neuron, 42, 9-21 (2004).

52) Díez-García J., Matsushita S., Mutoh H., Nakai J., Ohkura M., Yokoyama J., Dimitrov D., Knöpfel T., Eur. J. Neurosci., 22, 627635 (2005).

53) Reiff D. F., Ihring A., Guerrero G., Isacoff E. Y., Joesch M., Nakai J., Borst A., J. Neurosci., 25, 4766- 4778 (2005).

54) Heim N., Garaschuk O., Friedrich M. W., Mank M., Milos R. I., Kovalchuk Y., Konnerth A., Griesbeck O., Nat. Methods, 4, 127-129 (2007).

55) Mao T., O'Connor D. H., Scheuss V., Nakai J., Svoboda K., PLoS ONE, 3, e1796 (2008)

56) He J., Ma L., Kim S. S., Nakai J., Yu C. R., Science, 320, 535-538 (2008).

57) Hendel T., Mank M., Schnell B., Griesbeck O., Borst A., Reiff D. F., J. Neurosci., 28, 7399-7411 (2008).

58) Kuchibhotla K. V., Goldman S. T., Lattarulo C. R., Wu H. Y., Hyman B. T., Bacskai B. J., Neuron, 59, 214-225 (2008).
59) Mank M., Santos A. F., Direnberger S., Mrsic-Flogel T. D., Hofer S B., Stein V., Hendel T., Reiff D. F., Levelt C., Borst A., Bonhoeffer T., Hübener M., Griesbeck O., Nat. Methods, 5, 805-811 (2008).

60) Jayaraman V., Laurent G., Front. Neural Circuits, 1, 3 (2007).

61) Wallace D. J., Meyer zum Alten Borgloh S., Astori S., Yang Y., Bausen M., Kügler S., Palmer A. E., Tsien R. Y., Sprengel R., Kerr J. N., Denk W., Hasan M. T., Nat. Methods, 5, 797-804 (2008).

62) Mao B. Q., Hamzei-Sichani F., Aronov D., Froemke R. C., Yuste R., Neuron, 32, 883-898 (2001).

63) MacLean J. N., Watson B., Aaron R., Yuste R., Neuron, 48, 811823 (2005).

64) Buzsáki G., Nat. Neurosci., 7, 446- 451 (2004).

65) Peterlin Z. A., Kozloski J., Mao B. Q., Tsiola A., Yuste R., Proc. Natl. Acad. Sci. U.S.A., 97, 3619-3624 (2000).

66) Kozloski J., Hamzei-Sichani F., Yuste R., Science, 293, 868-872 (2001).

67) Aaron G., Yuste R., Synapse, 60, 437-440 (2006).

68) Crépel V., Aronov D., Jorquera I., Represa A., Ben-Ari Y., Cossart R., Neuron, 54, 105-120 (2007).

69) Goldin M., Epsztein J., Jorquera I., Represa A., Ben-Ari Y., Crépel V., Cossart R., J. Neurosci., 27, 9560—9572 (2007).

70) Le Bon-Jego M., Yuste R., Front. Neurosci., 1, 123-129 (2007).

71) Nikolenko V., Poskanzer K. E., Yuste R., Nat. Methods, 4, 943-950 (2007).

72) Matsuzaki M., Ellis-Davies G. C. R., Nemoto T., Miyashita Y., Iino M., Kasai H., Nat. Neurosci., 4, 1086-1092 (2001).

73) Ellis-Davies G. C. R., Chem. Rev., 108, 1603-1613 (2008)

74) Wang S., Szobota S., Wang Y., Volgraf M., Liu Z., Sun C., Trauner D., Isacoff E. Y., Zhang X., Nano Lett., 7, 3859-3863 (2007).

75) Lutz C., Otis T. S., DeSars V., Charpak S., DiGregorio D. A., Emiliani V., Nat. Methods, 5, 821-827 (2008).

76) Boyden E. S., Zhang F., Bamberg E., Nagel G., Deisseroth K., Nat. Neurosci., 8, 1263-1268 (2005).

77) Ishizuka T., Kakuda M., Araki R., Yawo H., Neurosci. Res., 54, 8594 (2006).

78) Zhang F., Wang L. P., Brauner M., Liewald J. F., Kay K., Watzke N., Wood P. G., Bamberg E., Nagel G., Gottschalk A., Deisseroth K., Nature (London), 446, 633-639 (2007).

79) Zhang F., Prigge M., Beyriére F., Tsunoda S. P., Mattis J., Yizhar O., Hegemann P., Deisseroth K., Nat. Neurosci., 11, 631-633 (2008).

80) Bernstein J. G., Han X., Henninger M. A., Ko E. Y., Qian X., Franzesi G.T., McConnell J. P., Stern P., Desimone R., Boyden E. S., Proc. Soc. Photo. Opt. Instrum. Eng., 6854, 68540H (2008).

81) Bhalla U. S., PLoS Comp. Biol., 4, e100098 (2008).

82) Hashemi M., Buibas M., Silva G. A., J. Neurosci. Methods, 170 , 294-299 (2008)

83) Ozden I., Lee H. M., Sullivan M. R., Wang S. S., J. Neurophysiol., 100, 495-503 (2008)

84) Yaksi E., Friedrich R. W., Nat. Methods, 3, 377-383 (2006).

85) Bontorin G., Renaud S., Garenne A., Alvado L., Le Masson G., Tomas J., Proc. IEEE Eng. Med. Biol. Soc., 2007, 3004-3007 (2007).

86) Göppert-Mayer M., Ann. Phys., 9, 273-295 (1931).

87) Peticolas W. L., Goldsborough J. P., Rieckhoff K. E., Phys. Rev. Lett., 10, 43-45 (1963)

88) Valdmanis J. A., Fork R. L., IEEE J. Quantum Electron, 22, 112 118 (1986).

89) Wise F. W., Walmsley C. L., Tang C. L., Opt. Lett., 13, 129-131 (1988)

90) Spence D. E., Kean P. N., Sibbert W., Opt. Lett., 16, $42-44$ (1991).

91) Denk W., Strickler J. H., Webb W. W., Science, 248, 73-76 (1990).

92) Helmchen F., Denk W., Nat. Methods, 2, 932-940 (2005).

93) Wise F. W., "Laser for Multiphoton Microscopy," ed. by Yuste R., Konnerth A., Cold Spring Harbor Laboratory Press, New York, 2005.

94) Stosiek C., Garaschuk O., Holthoff K., Konnerth A., Proc. Natl. Acad. Sci. U.S.A., 100, 7319-7324 (2003).

95) Ohki K., Chung S., Ch'ng Y. H., Kara P., Reid R. C., Nature (London), 433, 597-603 (2005).

96) Kerr J. N. D., Greenberg D., Helmchen F., Proc. Natl. Acad. Sci. U.S.A., 102, 14063-14068 (2005).

97) Mrisc-Flogel T. D., Hofer S. B., Ohki K., Reid R. C., Bonhoeffer T., Hübener M., Neuron, 54, 961—972 (2007).

98) Sato T. R., Gray N. W., Mainen Z. F., Svoboda K., PLoS Biol., 5, e189 (2007) 
99) Sohya K., Kameyama K., Yanagawa Y., Obata K., Tsumoto T., J. Neurosci., 27, 2145-2149 (2007).

100) Winship I. R., Plaa N., Murphy T. H., J. Neurosci., 27, 6268-6272 (2007).

101) Winship I. R., Murphy T. H., J. Neurosci., 28, 6592-6606 (2008).

102) Hubel D. H., Wiesel T. N., J. Physiol., 160, 106-154 (1962).

103) Bonhoeffer T., Grinvald A., Nature (London), 353, 429-431 (1991).

104) Weliky M., Bosking W. H., Fitzpatrick D. A., Nature (London), 379, 725-728 (1996).

105) Eichhoff G., Busche M. A., Garaschuk O., Eur. J. Nucl. Med. Mol. Imaging, 35, S99-S106 (2008).

106) Sacconi L., Tolic-Norrelykke I. M., Antolini R., Pavone F. S., J. Biomed. Opt., 10, $014002-014005$ (2005)

107) Hoy C. L., Durr N. J., Chen P., Piyawattanametha W., Ra H., Solgaard O., Ben-Yakar A., Opt. Exp., 16, 9996-10004 (2008).

108) Fetcho J. R., Cox K. J. A., O’Malley D. M., Histochem. J., 30, 153167 (1998).

109) Brustein E., Marandi N., Kovalchuk Y., Drapeau P., Konnerth A., Pflugers Arch., 446, 766-773 (2003).

110) Niell C. M., Smith S. J., Neuron, 45, 941—951 (2005).

111) Ramdya P., Reiter B., Engert F., J. Neurosci. Methods, 157, 230-237 (2006).

112) Bhatt D. H., McLean D. L., Hale M. E., Fetcho J. R., Neuron, 53, 91-102 (2007)

113) Yaksi E., Judkewitz B., Friedrich R. W., PLoS Biol., 5, 1-21 (2007).

114) Orger M. B., Kampff A. R., Severi K. E., Bollmann J. H., Engert F., Nat. Neurosci, 11, 327-333 (2008).

115) Hewapathirane D. S., Dunfield D., Yen W., Chen S., Hass K., Exp Neurol., 211, 480-488 (2008).

116) Ramdya P., Engert F., Nat. Neurosci., 11, 1083-1090 (2008).

117) Wang J. W., Wong A. M., Flores J., Vosshall L. B., Axel R., Cell, 112, $271-282(2003)$.

118) Galizia C. G., Kimmerle B., J. Comp. Physiol. A, 190, 21-38 (2003).

119) Moreaux L., Laurent G., Front. Neural Circuits, 1, 2 (2007).

120) Lin B. J., Chen T. W., Schild D., J. Physiol., 582, 163-175 (2007).

121) Göbel W., Kampa B. M., Helmchen F., Nat. Methods, 4, 73-79 (2007).

122) Göbel W., Helmchen F., J. Neurophysiol., 98, 3770-3779 (2007).

123) Saggau P., Curr. Opin. Neurobiol., 16, 543-550 (2006).

124) Brillouin L., Ann. Phys. (Paris), 17, 88-122 (1922).

125) Debye P., Sears F. W., Proc. Natl. Acad. Sci. U.S.A., 18, 409-414 (1932).

126) Uchida N., Niizeki N., Proc. IEEE, 61, 1073-1092 (1971)

127) Goldstein S. R., Hubin T., Rosenthal S., J. Microsc., 157, 29-38 (1990).

128) Bullen A., Patel S. S., Saggau P., Biophys. J., 73, 477-491 (1997).

129) Salomé R., Kremer Y., Dieudonné S., Léger J. F., Krichevsky O., Wyart C., Chatenay D., J. Neurosci. Methods, 154, 161-174 (2006).

130) Iyer V., Hoogland T. M., Saggau P., J. Neurophysiol., 95, 535-545 (2006).

131) Roorda R. D., Hohl T. M., Toledo-Crow R., Miesenböck G., J. Neurophysiol., 92, 609-621 (2004).

132) Zeng S., Lv X., Zhan C., Chen W. R., Xiong W., Jacques S. L., Luo Q., Opt. Lett., 31, 1091-1093 (2006).

133) Reddy G. D., Saggau P., J. Biomed. Opt., 10, 64038 (2005).

134) Vučinić D., Sejnowski T. J., PLoS ONE, 2, e699 (2007).

135) Reddy G. D., Kelleher K., Fink R., Saggau P., Nat. Neurosci., 11, $713-620$ (2008).

136) Otsu Y., Bormuth V., Wong J., Mathieu B., Dugué G. P., Feltz A., Dieudonné S., J. Neurosci. Methods, 173, 259-270 (2008).

137) Liang M., Stehr R. L., Krause A. W., Opt. Lett., 22, 751-753 (1997).

138) Hanley Q. S., Verveer P. J., Gemkow M. J., Arndt-Jovin D., Jovin T. M., J. Microsc. Oxford, 196, 317-331 (1999).

139) Bansal V., Ratel S., Saggau P., J. Biomed. Opt., 11, 34004 (2006).

140) Bewersdorf J., Pick R., Hell S. W., Opt. Lett., 23, 655-657 (1998).

141) Nielsen T., Hellweg F. D., Anderson P., J. Microsc., 201, 368-376 (2001)

142) Niesner R., Anderson V., Neumann J., Spiecker H., Gunzer M., Biophys. J., 93, 2519-2529 (2007).

143) Kim K. H., Buehler C., Bahlmann K., Ragan T., Lee W. C. A., Nedivi E., Heffer E. L., Fantini S., So P. T. C., Opt. Exp., 15, 11658-11678 (2007).
144) Ji N., Magee J. C., Betzig E., Nat. Methods, 5, 197-202 (2008).

145) Kurtz R., Fricke M., Kalb J., Tinnerfeld P., Sauer M., J. Neurosci. Methods, 151, 276-286 (2006).

146) Fuchs E., Jaffe J. S., Long R. A., Azam F., Opt. Exp., 10, 145-154 (2002).

147) Huisken J., Swoger J., Del Bene F., Wittbrodt J., Stelzer E. H., Science, 305, 1007-1009 (2004).

148) Engelbrecht C. J., Stelzer E. H. K., Opt. Lett., 31, 1477-1479 (2006).

149) Dodt H. U., Leischner U., Schierloh A., Jährling N., Mauch C. P., Deininger K., Deussing J. M., Eder M., Zieglgänsberger W., Becker K., Nat. Methods, 4, 331-336 (2007).

150) Holekamp T. F., Turaga D., Holy T. E., Neuron, 57, 661-672 (2008).

151) Theer P., Hasan M. T., Denk W., Opt. Lett., 28, 1022-1024 (2003).

152) Theer P., Denk W., J. Opt. Soc. Am. A, 23, 3139-3149 (2006).

153) Nemoto T., Mol. Cells, 26, 113-120 (2008).

154) Mehta A. D., Jung J. C., Flusberg B. A., Schnitzer M. J., Curr. Opin. Neurobiol., 14, 617-628 (2004).

155) Kudo Y., Akita K., Nakamura T., Ogura A., Makino T., Tamagawa A., Ozaki K., Miyakawa A., Neuroscience, 3, 619-625 (1992).

156) Murayama M., Pérez-Garci E., Lüscher H. R., Larkum M. E., J. Neurophysiol., 98, 1791-1805 (2007).

157) Adelsberger H., Garaschuk O., Konnerth A., Nat. Neurosci., 8, 998 990 (2005).

158) Fukuda Y., Kawano Y., Tanikawa Y., Oba M., Koyama M., Takagi H., Matsumoto M., Nagayama K., Setou M., Neurosci. Lett., 400, 5357 (2006).

159) Moore D. T., Appl. Opt., 19, 1035-1038 (1980).

160) Jung J. C., Schnitzer M. J., Opt. Lett., 28, $902-904$ (2003).

161) Jung J. C., Mehta A. D., Aksay E., Stepnoski R., Schnitzer M. J., J. Neurophysiol., 92, 3121-3133.

162) Levene M. J., Dombeck D. A., Kasischke K. A., Molloy R. P., Webb W. W., J. Neurophysiol., 91, 1908-1912 (2004).

163) Ikeda M., Matsushita A., J. Neurosci. Methods, 2, 9-17 (1980).

164) Hirano M., Yamashita Y., Miyakawa A., Anal. Sci., 9, 375-380 (1993).

165) Knight J. C., Russell P. S. J., Science, 296, 276-277 (2002).

166) Knight J. C., Nature (London), 424, 847-851 (2003).

167) Berg-Johnsen J., Langmoen I. A., Acta Anaesthesiol. Scand., 36, 350-355 (1992).

168) Pare D., Lang E. J., Destexhe A., Neuroscience, 84, 377-402 (1998).

169) Steriade M., Timofeev I., Greiner F., J. Neurophysiol., 85, 1969 1985 (2001)

170) Cotillon-Williams N., Edeline J. M., J. Neurophysiol., 89, 1968 1984 (2003).

171) Rudolph M., Pospischil M., Timofeev I., Destexhe A., J. Neurosci., 27, 5280-5290 (2007).

172) Helmchen F., Fee M. S., Tank D. W., Denk W., Neuron, 31, 903-912 (2001).

173) Engelbrecht C. J., Johnston R. S., Seibel E. J., Helmchen F., Opt. Exp., 16, 5556-5564 (2008).

174) Flusberg B. A., Cocker E. D., Piyawattanametha W., Jung J. C., Cheung E. L. M., Schnitzer M. J., Nat. Methods, 2, 941—950 (2005).

175) Sawinski J., Denk W., J. Appl. Phys., 102, 034701 (2007).

176) Myaing M. T., MacDonald D. J., Li X., Opt. Lett., 31, 1076-1078 (2006).

177) Myaing M. T., Ye J. Y., Norris T. B., Thomas T., Baker J. R. Jr., Wadsworth W. J., Bouwmans G., Knight J. C., Russell P. St. J., Opt. Lett., 28, 1224-1226 (2003).

178) Göbel W., Kerr J. N. D., Nimmerjahn A., Helmchen F., Opt. Lett., 29, $2521-2523$ (2004)

179) Fu L., Gan X., Gu M., Opt. Exp., 13, 5528-5534 (2005).

180) Xie H., Pan Y., Fedder G. K., Sensor Actuat. A-Phys., 103, 237-241 (2003).

181) Piyawattanametha W., Barretto R. P. J., Ko T., Flusberg B. A., Cocker E. D., Ra H., Lee D., Solgaard O., Schnitzer M. J., Opt. Lett., 31, 2018-2020 (2006).

182) Kim D., Kim K. H., Yazdanfar S., So P. T. C., Proc. SPIE, 5323, $267-272(2004)$

183) Kim D., Kim K. H., Yazdanfar S., So P. T. C., Proc. SPIE, 5700, 14 22 (2005).

184) Kerfoot W. B., Science, 162, 477 (1968).

185) Dahmen H. J., Experientia, 36, 685-687 (1980).

186) van Tilborg M., van der Pers J. N. C., Roessingh P., Sabelis N. W., 
Behav. Res. Methods Instrum. Comput., 35, 478-482 (2003).

187) Mason A. C., Oshinsky M. L., Hoy R. R., Nature (London), 410 , 686-690 (2001).

188) Dombeck D. A., Khabbaz A. N., Collman F., Adelman T. L., Tank D. W., Neuron, 56, 43-57 (2007).

189) Robert D., J. Comp. Physiol. A, 164, 15-24 (1988).

190) Möhl B., J. Comp. Physiol. A, 163, 803-812 (1988).

191) Kimmerle B., Eickermann J., Egelhaaf M., J. Exp. Biol., 203, 1723 1732 (2000).

192) Gray J. R., Pawlowski V., Willis M. A., J. Neurosci. Methods, 120 $211-223$ (2002).

193) Taylor G. K., Bacic M., Bomphrey R. J., Carruthers A. C., Gillies J.,
Walker S. M., Thomas A. L. R., J. Exp. Biol., 211, 258-266 (2008).

194) Hölscher C., Schnee A., Dahmen H., Seita L., Mallot H. A., J. Exp. Biol., 208, 561-569 (2005).

195) Hirose M., IEEE Multimedia Mag., 4, 27-33 (1997).

196) Sanchez-Vives M. V., Slater M., Nat. Rev. Neurosci., 6, 332-339 (2005).

197) Germain R. N., Miller M. J., Dustin M. L., Nussenzweig M. C., Nat. Rev. Immunol., 6, 497-507 (2006).

198) Bullen A., Nat. Rev. Drug Discov., 7, 54-67 (2008).

199) Niesner R., Anderson V., Gunzer M., Immunol. Rev., 221, 7-15 (2008). 